\title{
Investigation of Stress Perceptions of Physical Education Teachers
}

\author{
Çağrı Hamdi ERDOĞAN ${ }^{1 *}$ \\ Ramazan TOPUZ ${ }^{(\mathbb{D}}$ \\ 'Ministry of Education, Şehit Ahmet Cihan Kilci Middle School, Kayseri, Turkey. \\ Email:erdoganhamdi@hotmail.com Tel: +903524271213 \\ ${ }^{2}$ Selcuk University, Faculty of Sport Sciences, Konya, Turkey. \\ Email:ramazan_topuzz@hotmail.com Tel:+903s22411606
}

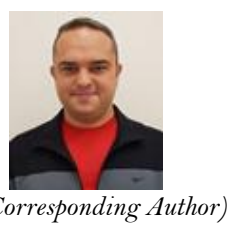

\section{Abstract}

The aim of this study is to investigate the stress perceptions of physical education teachers and determine these perceptions in terms of certain variables. In the study, a descriptive survey method was used, which aimed at revealing the existing situation. The research group was comprised of 320 physical education teachers actively working in the state schools of Kayseri province in the 2019-2020 education year. In the study, Personal Information Form and Perceived Stress Scale were used as the data collection tools. SPSS program was used for the analysis of the data. Techniques of $t$ test (independent-samples $t$ test) for paired comparisons and one-way analysis of variance (one-way anova) for multiple comparisons were used in the research study. According to the research results, the stress perceptions of the physical education teachers were determined as "moderate". Additionally, it was determined that there was statistically no significant difference among the stress perceptions of physical education teachers concerning their gender, age, marital status, sport branch, professional experience, monthly income perception, school type, and school location.

Keywords: Physical education, Sports, Psychology, Teacher, Stress, Perception.

Citation | Çağrı Hamdi ERDOĞAN; Ramazan TOPUZ (2020). Investigation of Stress Perceptions of Physical Education Teachers. Asian Journal of Education and Training, 6(2): 144-148.

History:

Received: 6 December 2019

Revised: 15 January 2020

Accepted: 18 February 2020

Published: 20 March 2020

Licensed: This work is licensed under a Creative Commons

Attribution 3.0 License (œ) Er

Publisher: Asian Online Journal Publishing Group
Acknowledgement: Both authors contributed to the conception and design of the study.

Funding: This study received no specific financial support.

Competing Interests: The authors declare that they have no conflict of interests.

Transparency: The authors confirm that the manuscript is an honest, accurate, and transparent account of the study was reported; that no vital features of the study have been omitted; and that any discrepancies from the study as planned have been explained.

Ethical: This study follows all ethical practices during writing

\section{Contents}

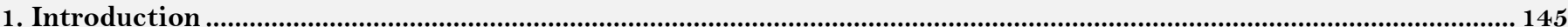

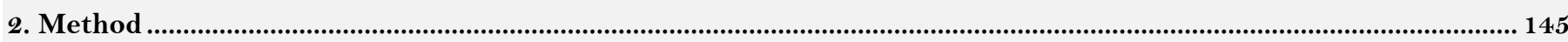

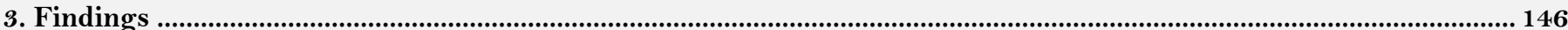

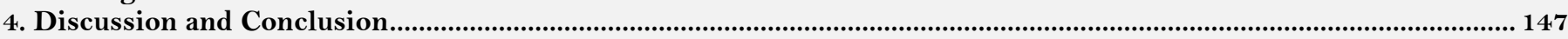

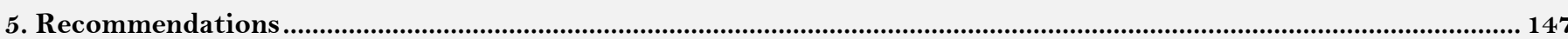

References 


\section{Contribution of this paper to the literature}

This study contributes to existing literature by investigating the stress perceptions of physical education teachers and determines these perceptions in terms of certain variables.

\section{Introduction}

In the twenty-first century, people live in a continuous struggle. In today's world, the value of individuals has become measured by what they have. Being successful requires being in good condition in material terms, an effort to compete with opponents all the time. This urges people constantly to develop, renew, and push their boundaries. This competitive environment also invites many problems that will arise. Among these, the leading problem is stress that have serious and adverse effects on human health (Karadavut, 2005).

The stress, which is the problem of modern times, has become a natural part of our lives as a result of being a modern society and living very fast and active. In our century, people push their own talents and boundaries for a large part of their lives irrespective of their profession. Regardless of working under state or private institutions, or self-employed without a connection with any institution, it is inevitable to meet the concept of stress (Arican, 2011).

Stress is a condition that occurs by threatening and forcing the organism's physical and mental limits (Gibbons, 2012). Stress is the overstimulation status at physical and psychological dimensions that occurs when the factors caused by internal and external environment are considered threatening or harmful by the individual (Lazarus \& Folkman, 1984). Stress is expressed as the resistance of the individual against the deterioration of the psychological and biological structure causing from the effect of external forces (Güçlü, 2001). Stress is the effort of the person exceeding his physical and psychological boundaries due to adverse conditions caused by the physical and social environment (Cüceloğlu, 2000).

Stress can be defined as a condition that occurs when the physical and spiritual integrity is forced, as well as factors that force and disrupt individual integrity (Tekin, Yazgan Cilesiz, \& Gede, 2019). People can be exposed to stress conditions that negatively affect their mental health and psychological state in everyday life, cause pessimism, and lead to despair (Yıldız, Güç, \& Erdem, 2015).

Stress is a concept that affects behaviors, human relationships, business performance, and social life of people. Stress does not occur spontaneously and suddenly, but it is a situation that is triggered by individual and environmental factors. In order for stress to occur, the changes in the environment in which one lives must affect the individual. Every person is affected by the changes in the environment. Some individuals are affected less and slowly, some are affected at higher levels and faster. Therefore, stress is the effects of changes in the environment, where the life of an individual is going on, or the effects caused by the changes the individual applies (Gül, 2015).

As a result of the exposure to the stress-causing event, various reactions arise in our body. These reactions, which continue for a long time period, cause disorders in the long period. When people face a stress-causing situation, they either show effort to fight and overcome them, or avoid problems by applying the avoidance mechanism (Eriksen, 2011).

The perceptions of stress of physical education teachers, who have an important place within the education system, are of interest and importance to investigate. In addition, investigating the stress perceptions of physical education teachers will contribute to the literature. In this study, it was aimed at examining the stress perceptions of physical education teachers. In addition, the stress perceptions of physical education teachers were compared in terms of certain characteristics.

\section{Method}

\subsection{Research Model}

This was a research that was designed in the descriptive survey model. Survey research is defined as the study, which aims at collecting data to determine certain features of a group (Büyüköztürk, Kılıç Cakmak, Akgün, Karadeniz, \& Demirel, 2010).

\subsection{Research Group}

The research group was comprised of 320 physical education teachers who were actively working in the 20192020 education year in public schools in Kayseri province, Turkey, and were randomly selected. Of the physical education teachers in the research group, 131 (40.9\%) were female and $189(59.1 \%)$ were male; $205(64.1 \%)$ were married and $115(35.1 \%)$ were single.

\subsection{Data Collection Tools}

In this study, which was conducted to determine the stress perceptions of physical education teachers and compare them through certain characteristics, the Personal Information Form and Perceived Stress Scale were used as the data collection tools. The Personal Information Form was developed by the researchers in order to determine the demographic characteristics of the physical education teachers in the research group.

The Perceived Stress Scale was developed by Cohen, Kamarck, and Mermelstein (1983) to measure stress perceptions of individuals. The Perceived Stress Scale is a five-point Likert-type scale consisting of 14 items. Participants evaluate each item between 0 and 4 (Never-0, and Very Often-4). 7 of the items are scored inversely. The total scores from the scale range from 0 to 56. The high score on the scale indicates that the person's stress perception is above normal. Perceived Stress Scale was translated into Turkish by Eskin, Harlak, Demirkıran, and Dereboy (2013). Eskin et al. (2013) reported that the internal consistency coefficient of the scale was calculated as .84 and the test-repeat-test reliability coefficient was calculated as .87.

\subsection{Statistical Analyses}

SPSS program was used for statistical analysis. The arithmetic average $(\bar{X})$ and standard deviation $(\mathrm{Sd})$ techniques were used as descriptive statistics in order to examine the subjective stress perceptions of physical 
education teachers. It was determined, through the Kolmogorov-Smirnov test, that the stress perceptions of the physical education teachers in the research group demonstrated a normal distribution ( $\mathrm{p}>0.05)$ Also in the comparisons made; $T$ test method was used for paired comparisons, for independent groups and one way analysis of variance method (one way anova) was used for multiple comparisons. $p<0.05$ was taken as the criterion when the significance (p) levels were interpreted.

\section{Findings}

Table-1. Distribution of demographic characteristics of the physical education teachers in the research group.

\begin{tabular}{l|c|c|l|c|c}
\hline Gender & $\mathbf{N}$ & $\mathbf{\%}$ & Marital Status & $\mathbf{N}$ & $\mathbf{\%}$ \\
\hline Female & 131 & 40.9 & Married & 205 & 64.1 \\
\hline Male & 189 & 59.1 & Single & 115 & 35.9 \\
\hline Age & $\mathrm{N}$ & $\%$ & Professional Experience & $\mathrm{N}$ & $\%$ \\
\hline 20-29 Years old & 111 & 34.7 & O-9 Years & 155 & 48.4 \\
\hline 30-39 Years old & 126 & 39.4 & $10-19$ Years & 114 & 35.6 \\
\hline 40-49 Years old & 83 & 25.9 & $20-29$ Years & 51 & 15.9 \\
\hline School Type & $\mathrm{N}$ & $\%$ & School Location & $\mathrm{N}$ & $\%$ \\
\hline Secondary School & 176 & 55.0 & Rural & 42 & 13.1 \\
\hline High School & 144 & 45.0 & Urban & 278 & 86.9 \\
\hline Monthly Income Perception & $\mathrm{N}$ & $\%$ & Sport Branch & $\mathrm{N}$ & $\%$ \\
\hline Low & 31 & 9.7 & Individual Sport & 117 & 36.6 \\
\hline Medium & 250 & 78.1 & Team Sport & 203 & 63.4 \\
\hline High & 39 & 12.2 & & & \\
\hline
\end{tabular}

The demographic characteristics of physical education teachers in the research group are presented in Table 1. It was determined that $131(40.9 \%)$ physical education teachers in the research group were female, $189(59.1 \%)$ were male; $205(64.1 \%)$ were married, 115 (35.9\%) were single; $111(34.7 \%)$ were in the 20-29 age group, 126 $(39.4 \%)$ were in the 30-39 age group, and 83 (25.9\%) were in the 40-49 age group. Additionally, 155 (48.4\%) physical education teachers in the research group had a professional experience of 0-9 years, 114 (35.6\%) had 10-19 years, and $51(15.9 \%)$ had 20-29 years; $176(55 \%)$ of them worked in secondary schools and $144(45 \%)$ were working in high schools; $42(13.1 \%)$ of them were working in rural area, while $278(86.9 \%)$ were working in urban areas; the branch of $117(36.6 \%)$ of the physical education teachers was individual sport, while it was team sport for $203(63.4 \%)$ of them; the monthly income perceptions of $31(9.7 \%)$ physical education teachers was low, it was medium for $250(78.1 \%)$ and high for $39(12.2 \%)$.

Table-2. The mean score of the physical education teachers in the research group obtained from the overall perceived stress scale.

\begin{tabular}{c|c|c|c}
\hline Scale & N & $\bar{X}$ & Sd \\
\hline Perceived Stress Scale & 320 & 22.98 & 6.810 \\
\hline
\end{tabular}

The results concerning the overall Perceived Stress Scale scores of the physical education teachers in the research group are presented in Table 2 . As a result of the analysis, physical education teachers in the research group gained $\bar{X}=22.98$ mean score from the overall perceived stress scale. Based on this result, the stress perceptions of the physical education teachers in the research group were determined as "moderate".

Table-3. Comparison of the stress perceptions of physical education teachers in the research group concerning their gender, marital status, school type, school location, and sport branch.

\begin{tabular}{l|c|c|l|c|c|c}
\hline Gender & $\mathbf{N}$ & $\overline{\mathrm{X}}$ & $\mathbf{S d}$ & $\mathbf{t}$ & $\mathbf{p}$ & Difference \\
\hline Female & 131 & 22.82 & 7.042 & -.342 & .732 & No \\
\hline Male & 189 & 23.08 & 6.662 & & & \\
\hline Marital Status & $\mathrm{N}$ & $\overline{\mathrm{X}}$ & $\mathrm{Sd}$ & $\mathrm{t}$ & $\mathrm{p}$ & Difference \\
\hline Married & 205 & 23.40 & 7.061 & 1.471 & .142 & No \\
\hline Single & 115 & 22.23 & 6.300 & & & \\
\hline School Type & $\mathrm{N}$ & $\overline{\mathrm{X}}$ & $\mathrm{Sd}$ & $\mathrm{t}$ & $\mathrm{p}$ & Difference \\
\hline Secondary School & 176 & 22.39 & 7.087 & -1.699 & .090 & No \\
\hline High School & 144 & 23.69 & 6.409 & & & \\
\hline School Location & $\mathrm{N}$ & $\overline{\mathrm{X}}$ & $\mathrm{Sd}$ & $\mathrm{t}$ & $\mathrm{p}$ & Difference \\
\hline Rural & 42 & 23.30 & 5.270 & .335 & .738 & No \\
\cline { 1 - 3 } Urban & 278 & 22.93 & 7.020 & & & \\
\hline Individual Sport & 117 & 23.94 & 6.266 & 1.920 & .056 & No \\
\hline Team Sport & 203 & 22.42 & 7.061 & & & \\
\hline Total & 320 & 22.98 & 6.810 & & & \\
\hline
\end{tabular}

The results concerning the comparisons of stress perceptions of the physical education teachers in the research group in terms of gender, marital status, school type, school location, and sport branch are given in Table 3. According to the analysis results, it was determined that there was statistically no significant difference among the stress perceptions of the physical education teachers in the research group concerning the marital status, school type, school location, gender, and sport branch. 
Table-4. The comparison of the physical education teachers in the research group about their stress perceptions in terms of age, professional experience, and monthly income perceptions.

\begin{tabular}{|c|c|c|c|c|c|c|}
\hline Age & $\mathbf{N}$ & $\bar{X}$ & Sd & $\mathbf{F}$ & $\mathrm{p}$ & Difference \\
\hline 20-29 Years old & 111 & 23.37 & 6.102 & \multirow{3}{*}{1.315} & \multirow{3}{*}{.270} & \multirow{3}{*}{ No } \\
\hline 30-39 Years old & 126 & 23.31 & 6.839 & & & \\
\hline 40-49 Years old & 83 & 21.93 & 7.597 & & & \\
\hline Professional Experience & $\mathrm{N}$ & $\bar{X}$ & $\mathrm{Sd}$ & $\mathrm{F}$ & $\mathrm{p}$ & Difference \\
\hline O-9 Years & 155 & 23.00 & 6.224 & \multirow{3}{*}{.175} & \multirow{3}{*}{.840} & \multirow{3}{*}{ No } \\
\hline 10-19 Years & 114 & 23.16 & 7.506 & & & \\
\hline 20-29 Years & 51 & 22.49 & 6.995 & & & \\
\hline Monthly Income Perception & $\mathrm{N}$ & $\bar{X}$ & $\mathrm{Sd}$ & $\mathrm{F}$ & $\mathrm{p}$ & Difference \\
\hline Low & 31 & 22.29 & 7.929 & \multirow{3}{*}{.176} & \multirow{3}{*}{.839} & \multirow{3}{*}{ No } \\
\hline Medium & 250 & 23.06 & 6.615 & & & \\
\hline High & 39 & 23.02 & 7.249 & & & \\
\hline Total & 320 & 22.98 & 6.810 & & & \\
\hline
\end{tabular}

The results concerning the comparisons of stress perceptions of the physical education teachers in the research group in terms of age, professional experience, and monthly income perceptions are given in Table 4. According to the analysis results, it was determined that there was statistically no significant difference among the stress perceptions of the physical education teachers in the research group concerning age, professional experience, and monthly income perception.

\section{Discussion and Conclusion}

In this research study, the stress perceptions of the physical education teachers were investigated. According to the research results, the stress perceptions of the physical education teachers were determined as "moderate". Additionally, it was determined that there was statistically no significant difference among the stress perceptions of physical education teachers concerning gender, age, marital status, sport branch, professional experience, monthly income perception, school type, and school location.

As a result of the research studies conducted by Savci and Aysan (2014); Caz, Aydoğdu, Tunçkol, and Oncü (2015); Baştuğ, Duman, Akçakoyun, and Karadeniz (2016); Ekiz (2016); Eraslan (2016); Hancioğlu (2017); Gözeler (2018); Sahin (2018) and Yildiz (2018) it was determined that there were statistically significant differences in the stress perceptions of the participants. This study contradicts the results of the abovementioned studies concerning the gender variable. Taş (2013); Bayram, Keskin, and Derebaşı (2016) and Yildiz (2018) determined that there was statistically no significant difference among the stress perceptions of the participants in terms of gender. This study is in parallel with the results of these research studies in terms of gender variable.

Cam and Nur (2015); Yanik (2017) and Mert (2019) found significant differences among the stress perceptions based on the age variable. This research study is not in parallel with the results of these research studies concerning the age variable. Taș (2013); Bayram et al. (2016); Eraslan (2016) and Hancioğlu (2017) did not detect a significant difference in the stress perceptions concerning the age variable. This study is in parallel with the results of these research studies in terms of age variable.

As a result of a study conducted by Tas (2013) it was determined that there was statistically no significant difference among stress perceptions of the participants concerning the marital status variable. This study is in parallel with the results of the mentioned research concerning the marital status variable. As a result of research studies conducted by Ateşoğlu and Erkal (2016); Sanlı (2017); Yanik (2017) and Mert (2019) it was determined that there were statistically significant differences among stress perceptions of the participants concerning the professional experience. This research contradicts the results of those studies in terms of the professional experience variable. As a result of a study conducted by Mert (2019) it was determined that there was a statistically significant difference among the stress perceptions of participants concerning their monthly income perceptions. This study contradicts the results of the mentioned study concerning the monthly income perception variable.

As a result of the research studies conducted by Savci and Aysan (2014); Cam and Nur (2015); Eraslan (2016) Sanlı (2017); Yağmur and Türkmen (2017); Yıldız (2017); Sahin (2018); Yildiz (2018) and Turan, Durgun, Kaya, Ertaş, and Kuvan (2019) it was determined that the stress perceptions of participants were determined as "moderate". This research is in parallel with the results of the abovementioned studies. Doğaner (2017) determined that the stress perceptions of the participants were "low", while Pınar et al. (2014); Bayram et al. (2016) and Ergin, Cevik, and Pakiş (2018) identified it as "high". This study contradicts the results of the mentioned research studies.

According to the results of this research, determining the stress perceptions of the physical education teachers as "moderate" can be considered as a positive outcome. High stress perception can have the possibility of causing psychological damage to the educators. Therefore, it can be considered as an important determination that the physical education teachers should not have high stress perceptions.

\section{Recommendations}

In order to reduce stress perception, conferences and seminars can be organized by the psychologists for the physical education teachers. The factors that can increase the stress perceptions of the physical education teachers can be investigated through various studies. Similar research studies can be conducted with different research groups for contributing to the literature. It is considered useful that the stress perception of the physical education teachers be investigated through qualitative research studies. Additionally, it is considered that increasing the socio-cultural activities among teachers in the school will have a positive effect on physical education teachers against stress. 


\section{References}

Arican, K. (2011). The sources of organizational stress. Journal of Education and Humanities: Theory and Practice, 2(4), 55-76.

Ateşoğlu, L., \& Erkal, S. (2016). Examination of the perceived stress levels of housekeeping staff in hospitals. The Journal of Academic Social Sciences, 29(4), 557-573.

Baştuğ, G., Duman, S., Akçakoyun, F., \& Karadeniz, F. (2016). Football referees; Stress, self-confidence, decision making In football referees; stress, self-confidence, decision making. Journal of Human Sciences, 13(3), 5399-5406. Available at: https://doi.org/10.14687/jhs.v13i3.4213.

Bayram, L., Keskin, Ö. D. Y., \& Derebaşı, D. G. (2016). Investigation of perceived stress levels of university students in terms of various variables. The Black Sea Journal of Social Sciences, 8(14), 291-302.

Büyüköztürk, S., Kılıç Cakmak, E., Akgün, O. E., Karadeniz, S., \& Demirel, F. (2010). Scientific research methods (7th ed.). Ankara: Pegem Academy Publications.

Cam, H. H., \& Nur, N. (2015). The relationship between perceived stress and gastrointestinal symptoms in nursing and midwifery students. TAF Preventive Medicine Bulletin, 14(6), 473-480.

Caz, C., Aydoğdu, V., Tunçkol, H., \& Oncü, E. (2015). The relationship between time management skill and stress: The example of physical education and sport school students. Academic Overview International Refereed Journal of Social Sciences, 50(2), $278-287$.

Cohen, S., Kamarck, T., \& Mermelstein, R. (1983). A global measure of perceived stress. Journal of Health and Social Behavior, 24(4), 385-396. Available at: https://doi.org/10.2307/2136404.

Cüceloğlu, D. (2000). Human and behavior (10th ed.). Istanbul: Remzi Bookstore.

Doğaner, S. (2017). The effect of regular exercise program on individuals' stress, happiness, and leisure satisfaction levels. Doctoral Dissertation, Ankara University, Institute of Health Sciences.

Ekiz, O. (2016). An analysis of perceived stress level (PSL) and healty life style behaviours of the university students studying sports and health. Master's Thesis, Kahramanmaraş Sütçü İmam University, Institute of Health Sciences.

Eraslan, M. (2016). Assessment of perceived stress levels of kick-boxers based on age and gender variables Investigation of perceived stress levels of kick boxing athletes according to age and gender variables. Journal of Human Sciences, 13(3), 5069-5077. Available at: https://doi.org/10.14687/jhs.v13i3.4113.

Ergin, E., Cevik, K., \& Pakiş, C. S. (2018). Investigation of nursing students' perception of stress and coping behaviours of stress regarding education. Journal of Education and Research in Nursing, 15(1), 16-22.

Eriksen, L. (2011). Stress and happiness among adolescents with varying frequency of physical activity. Perceptual and Motor Skills, 113(2), 631-646. Available at: https://doi.org/10.2466/02.06.10.13.pms.113.5.631-646.

Eskin, M., Harlak, H., Demirkıran, F., \& Dereboy, Ç. (2013). Adapting the perceived stress scale into Turkish: Reliability and validity analysis. In New Symposium Journal, $51(3), 132-140$.

Gibbons, C. (2012). Stress, positive psychology and the national student survey. Psychology Teaching Review, 18(2), 22-30.

Gözeler, P. S. (2018). The relationship of marriage adjustment with stress and marital attributions. Master's Thesis, Maltepe University, Institute of Social Sciences.

Güçlü, N. (2001). Stress management. Gazi University Journal of Gazi Education Faculty, 21(1), 91-109.

Gül, A. (2015). The mediating role of the safety at work in the effect on the job stress of positive organisational behaviour: Sample of a university hospital. Doctoral Dissertation. Süleyman Demirel University, Institute of Social Sciences.

Hancıoğlu, Y. (2017). The investigation of relationship between perceived stress level of university students and styles of coping with stress. Journal of Management and Economics Research, 15(1), 130-149.

Karadavut, Y. (2005). The primary school teachers' occupational stress reasons, symptoms of stres and the ways of coping with stress. Master Thesis, Gazi University Institute of Educational Sciences.

Lazarus, R. S., \& Folkman, S. (1984). Stress, appraisal and coping. New York: Springer Publishing Company.

Mert, C. (2019). The relationship between commercial vehicle driver's perceived stress level and job satisfaction. Doctoral Dissertation. Haliç University, Graduate Education Institute.

Pınar, S. E., Arslan, S., Polat, K., Ciftçi, D., Cesur, B., \& Dağlar, G. (2014). Examining the association of perceived stress with sleep quality in pregnancy. Dokuz Eylul University E-Journal of Nursing Faculty, 7(3), 171-177.

Sahin, A. (2018). Investigation of perceived stress levels of university students according to faculty type and gender variables. Kilis 7 Aralik University Journal of Physical Education and Sports Sciences, 2(1), 28-35.

Sanl, O. (2017). Analysing the perceived stress level of teachers with regards to some variables. Electronic Journal of Social Sciences, 16(61), 385-396.

Savci, M., \& Aysan, F. (2014). The relationship between the perceived stress level and the stress coping strategies in university students. The International Journal of Turkish Education Sciences, 3(2), 44-56.

Taş, S. (2013). Assessment of psychological resilience, percevied stress and depression in nurses working in Düzce University Hospital. Master's Thesis, Düzce University Institute of Health Sciences.

Tekin, E., Yazgan Cilesiz, Z., \& Gede, S. (2019). A research on the ways of coping with stress and perceived stress levels of employees in different professions. Ordu University Journal of Social Science Research, 9(1), 79-89.

Turan, N., Durgun, H., Kaya, H., Ertaş, G., \& Kuvan, D. (2019). The relationship between stress status and cognitive flexibility levels of nursing students. Journal of Academic Research in Nursing, 5(1), 59-66.

Yağmur, T., \& Türkmen, S. N. (2017). The level of stress perceived by the family members providing care for the individuals with mental illness and psychological endurance. Celal Bayar University Health Sciences Institute Journal, 4(1), 542-548.

Yanik, A. (2017). A research on the level of stress perceived by professional accountants. International Journal of Economic Research, 3(1), 99107.

Yildiz, K. (2018). Investigation of time management and stress perceptions of education faculty students. Sakarya University Journal of Education, 8(3), 80-99. Available at: https://doi.org/10.19126/suje.413286.

Yıldız, M. (2017). Investigation of the relationship between stress perception and mental status among bank employees. Master's Thesis, Işık University, Institute of Social Sciences.

Yıldız, M., Güç, K., \& Erdem, S. (2015). Examine attitudes to cope with stress in terms of human values: A study on public employees. Science Journal of Turkish Military Academy, 25(1), 41-62. 